\title{
STRATEGI REKRUTMEN PESERTA DIDIK BARU DALAM MASA PANDEMI COVID-19 DI SMK DARUSSALAM
}

\author{
Eko Budiywono ${ }^{1}$, Liya Kholifatus Sholekhah ${ }^{2}$ \\ e-mail: ekobudiywono@iaida.ac.id ${ }^{1}$, liyakholifa12@gmail.com ${ }^{2}$ \\ Prodi Manajemen Pendidikan Islam \\ Institut Agama Islam Darussalam Blokagung Tegalsari Banyuwangi
}

\begin{abstract}
Abstrak
Pada tahun 2019 dunia dihebohkan oleh wabah covid-19 yang berasal dari Wuhan Cina, masuk di Indonesia pada akhir bulan februari, wabah ini begitu sangat meresahkan karena penularannya begitu cepat dan tidak terlihat. Semua mekanisme pembelajaran masa pandemi ini berbeda dengan tahun sebelumnya. Tetapi semua itu tidak menyurutkan peminat calon peserta didik untuk mendaftar di SMK Darussalam Blokagung peneliti menduga ada strategi yang diterapkan dalam rekrutmen peserta didik baru. Permasalahan penelitianya yaitu strategi rekrutmen peserta didik baru dan faktor pendukung penghambat dalam masa pandemi Covid19. Subjek penelitianya yaitu kepala sekolah dan WKS. Kesiswaan selaku ketua panitia PPDB. Metode penelitian kualitatif, metode pengumpulan data observasi, wawancara dan dokumentasi, analisis data menggunakan analysis interactive model dari Miles Hubermen dan keabsahan data menggunakan trianggulasi. Hasil penelitian: strategi yang digunakan strategi promosi dan strategi seleksi. Pendukungnya meliputi guru, siswa-siswi dan alumni, semua media. Penghambatnya ada 2 internal yaitu letak geografis dan eksternal yaitu banyak orang tau wali murid yang protes tentang pembayaran. Tetapi semua itu bisa diatasi oleh SMK Darussalam Blokagung.
\end{abstract}

Kata Kunci: Strategi Rekrutmen, Masa Pandemi Covid-19

\begin{abstract}
In 2019 the world was stirred up by the Covid-19 outbreak originating from Wuhan, China, entering Indonesia at the end of February, this epidemic was so very disturbing because the transmission was so fast and invisible. All learning mechanisms during this pandemic were different from the previous year. But all of that did not dampen the interest of prospective students to register at SMK Darussalam Blokagung the researchers suspected that there was a strategy applied in the recruitment of new students. The research problem was the strategy of recruiting new students and the supporting factors that hindered the Covid-19 pandemic. The subject of the research was the principal of the school. and WKS. Kesiswaan as chairman of the PPDB committee. Qualitative research methods, data collection methods of observation, interviews and documentation, data analysis using an interactive model of Miles Hubermen and data validity using triangulation. The results of the study: the strategies used were promotion strategies and selection strategies. The supporters included teachers, students and alumni, all media. by SMK Darussalam Blokagung.
\end{abstract}

Keywords: Recruitment Strategy, Covid-19 Pandemic Period

\section{A. Pendahuluan}

Strategi Rekrutmen Peserta Didik Baru Dalam Masa Pandemi Covid-19 Di SMK Darussalam Eko Budiywono, Liya Kholifatus Sholekhah 
Dalam upaya meningkatkan pendidikan secara nasional disetiap satuan pendidikan, maka diarahkan pada upaya terselenggaranya layanan pendidikan pada masyarakat yang salah satunya merupakan penerimaan peserta didik baru. Menurut Kriswanto (2017:89) bahwa rekrutmen peserta didik merupakan pencarian dan menentukan peserta didik baru yang nantinya akan menjadi peserta didik di sekolah yang bersangkutan. Strategi rekrutmen peserta didik merupakan sistem pencarian, menentukan dan menarik pelamar yang mampu untuk menjadi peserta didik di lembaga tersebut.

Pada tahun 2019 dunia di hebohkan oleh wabah covid-19 yang berasal dari Wuhan Cina dan masuk di Indonesia pada akhir bulan februari 2019, wabah ini begitu sangat meresahkan karena penularannya yang begitu cepat dan tidak terlihat. Sehingga untuk memutus mata rantai penularan harus dilakukan beberapa kegiatan seperti pembatasan sosial. Terkait ini, Menteri pendidikan dan kebudayaan (Mendikbud) Nadiem Anwar Makarim juga langsung mengeluarkan surat edaran (SE). Surat Edaran Nomor 4 Tahun 2020 isinya tentang Pelaksanaan Kebijakan Pendidikan Dalam Masa Darurat Penyebaran Coronavirus Disease (Covid-19). Didalam surat edaran tersebut selain menjelaskan UN dibatalkan, juga menjelaskan mengenai pelaksanaan Penerimaan Peserta Didik Baru (PPDB) 2020.Semua mekanisme pembelajaran dan penilaian dalam masa pandemi ini berbeda dengan tahun-tahun sebelumnya.

Pada tahun 2020 SMK Darussalam Blokagung mengalami penurunan jumlah peserta didik. Namun setelah dilakukan berbagai inovasi melalui strategi-strategi yang telah disusun maka pada tahun 2021 jumlah peserta didik bertambah, bahkan sampai menutup pendaftaran. Berdasarkan data yang diperoleh menunjukkan bahwa jumlah peserta didik yang mendaftar di SMK Darussalam Blokagung telah mengalami peningkatan yang cukup signifikan.Peneliti menduga kemungkinan ada Strategi yang diterapkan dalam rekrutmen peserta didik baru.

Permasalahan pada penelitian ini yaitu (1) Strategi rekrutmen peserta didik baru dalam masa pandemi Covid-19 di Smk Darussalam Blokagung Banyuwangi. (2) 
faktor penghambat dan pendukung strategi rekrutmen peserta didik baru dalam masa pandemi Covid-19 di Smk Darussalam Blokagung Banyuwangi. Penelitian ini mempunyai tujuan untuk mengetahui strategi rekrutmen dan faktor penghambat pendukungnya.

Penelitian sebelumnya oleh Fauzan (2017) Stratetegi Rekrutmen Peserta Didik Baru Di MTs Satu Atap Hidayatul Mubtadi'in Purwojati Dan MTs Satu Atap Biroyatul Huda Cilongok Kabupaten Banyumas. Menyimpulkan bahwa strategi yang dilakukan secara bersamaan dengan MTs karena satu yayasan dan memanfaatkan kharima kyai dan ulama pendiri yayasan.

Penelitian selanjutnya dilakukan oleh Muhammad Janki Dausat (2017) Manajemen Strategik Dalam Penerimaan Peserta Didik Baru di MTs al Ikhlas Beji Kadungbanten Kabupaten Banyumas. Menyimpulkan bahwa manajemen strategik berawal dari (1) analisis lingkungan internal dan eksternal (2) formulasi strategi (3) implementasi strategi dalam penerimaan peserta didik baru.

\section{B. Metode Penelitian}

Menurut Sugiyono (2007:15) Penelitian ini merupakan jenis metode kualitatif yaitu: penelitian yang berlandaskan pada fisafat postpositivisme dimana kebenaran sesuai dengan hakikat objek. Digunakan untuk meneliti pada kondisi objek yang alamiah, dimana peneliti sebagai instrumen dan hasil penelitian lebih menekankan makna dari pada generalisasi.Dalam penelitian ini peneliti menggunakan sumber data berupa hasil observasi, hasil wawancara, dan dokumentasi tentang Strategi Rekrutmen Peserta Didik Baru Di SMK Darussalam.

Menurut Lofland (2006:57) sumber data utama dalam penelitian kualitatif adalah kata-kata dan tindakan, selebihnya adalah data tambahan seperti dokumentasi dan lain-lain. Secara garis besar sumber data yang digunakan dalam penelitian ada dua, yaitu:Sumber data primer merupakan data yang diperoleh melalui observasi dan wawancara langsung. Dalam penelitian ini sumber data primer diperoleh dari kepala 
sekolah dan WKS. Kesiswaan selaku ketua panitia PPDB SMK Darussalam Blokagung.Sumber data sekunder merupakan yang diperoleh secara langsung dari objek penelitian, data-data ini berasal dari data-data yang diperoleh dari dokumendokumen yang tersimpan dilembaga ini. Untuk mendapatkan data sekunder, peneliti menghimpun dari buku bacaan yang mengenai penelitian ini, arsip yang telah dipublikasikan maupun yang belum dipublikasikan di SMK Darussalam Darussalam. Hal ini, dilakukan agar peneliti memperoleh data-data tambahan yang belum didapatkan dari sumber data primer.

Dalam pengumpulan data ini ada beberapa teknik yang digunakan dalam rangka mengumpulkan data-data yang diperlukan. Menurut Sugiyono (2008:2) ada beberapa teknik cara pengumpulan data yang digunakan yaitu: Observasi disebut pula dengan pengamatan, yakni kegaiatan memusatkan perhatian terhadap suatu objek yang diteliti sambil mengamati dan mencatat secara sistematis hal-hal yang dianggap penting dan berkaitan dengan penelitian menggunakan panca indera. Jenis observasi yang digunakan dalam penelitian ini adalah obsevasi partisipatif. Dalam kegiatan observasi ini, penulis sebagai instrumen kunci terjun langsung mengadakan pengamatan terhadap hal-hal yang perlu dicatat dengan menggunakan pedoman observasi dan checklist dan yang terlibat langsung.Teknik observasi yang akan dilakukan dengan terjun langsung kelapangan secara aktif untuk memperoleh gambaran dan keterangan riil mengenai rekrutmen peserta didik baru. Keterangan dan informasi yang di peroleh akan dianalisis, ditafsirkan dan disimpulkan

Wawancara merupakan proses pengumpulan data yang langsung memperoleh informasi dari sumbernya (Harsono, 2008:165). Wawancara mendalam dapat diberikan makna kombinasi antara pertanyaan-pertanyaan deskriptif, struktural dan konterks.Wawancara yang akan dilakukan dengan mengajukan pertanyaanpertanyaan yang mungkin responden memberikan jawaban secara luas. Data yang diperoleh dari wawancara berupa pengalaman dan pengetahuan mengenai strategi rekrutmen peserta didik baru di SMK Darussalam. Dalam penelitian ini, wawancara 
akan dilakukan dengan narasumber yakni kepala sekolah dan panitia PPDB SMK Darussalam.

Menurut Harsono (2008:165), dokumentasi adalah pengambilan data yang diproses melalui dokumen-dokumen, metode dokumentasi dipakai untuk mengumpulkan data dari sumber-sumber dokumen yang mungkin mendukung atau bahkan berlawanan dengan hasil wawancara.Dalam penelitian ini, teknik dokumentasi yang akan dilakukan oleh peneliti dengan cara mmengumpulkan dokeumen-dokumen resmi yang berhubungan dengan Strategi Rekrutmen Peserta Didik Baru di SMK Darussalam.

Penelitian ini merupakan penelitian kualitatif. Maka analisis data dilakukan pada saat pengumpulan data berlangsung dan setelah pengumupulan data dalam periode tertentu, data yang dianalisis berupa kata-kata, kalimat-kalimat dan peristiwaperistiwa.Untuk menyajikan data agar lebih mudah dipahami maka langkah-langkah analisis data yang digunakan dalam penelitian ini adalah Analysis Interactive Model dari Miles dan Huberman, yang membagi langkah-langkah dalam kegiatan analisis data dengan beberapa bagian yaitu: (1) Pengumpulan datahasil wawancara, hasil observasi dan berbagai dokumen berdasarkan kategori yang sesuai dengan masalah penelitian, kemudian dikembangkan penjamin data melalui pencarian dan selanjutnya. (2) Reduksi datamerupakan suatu bentuk analisis yang menajamkan, menggolongkan, mengarahkan dan membuang data yang tidak diperlukan dan mengorganisasikan data dengan cara sedemikian rupa sehingga simpulan final dapat ditarik dan diverifikasi.Pada langkah ini data yang diperoleh dicatat dalam urain yang terperinci, dari data-data yang dicatat. Kemudian dilakukan penyederhanaan data. Data-data yang sudah dipilih hanya data yang berkaitan dengan masalah penelitian. (3) Penyajian Datamerupakan suatu rangkaian organisasi informasi yang memungkinkan kesimpulan riset dapat dilakukan. Penyajian data yang dimaksudkan untuk menemukan pola-pola ynag bermakna serta memberikan kemungkinan adanya penarikan simpulan serta memberikan tindakan. Menurut Sutopo menyatakan bahwa 
sajian data berupa narasi kalimat, gambar, jaringan kerja dan table sebagai narasinya.Pada langkah ini, data-data yang telah ditetapkan, kemudian disusun secara tersusun agar lebih mudah dipahami. Kemudian data-data dianalisis sehingga diperoleh deskripsi penelitian. (4) Penarikan kesimpulanmerupakan bagian dari suatu kegiatan konfigurasi yang utuh,kesimpulan-kesimpulan juga diverifikasi selama penelitian berlangsunng. dalam penarikan kesimpulan, penulis membuat kesimpulankesimpulan yang sifatnya obyektif dan terbuka, baik dari hasil wawancara, obsevasi maupun dari dokumentasi. Pada tahap ini, dibuatkan kesimpulan tentang hasil data yang diperoleh sejak awal penelitian. Kesimpulan ini masih memerlukan adanya verifikasi sehingga hasil yang diperoleh benar-benar valid.

\section{Hasil dan Pembahasan}

Setelah data sudah diketahui, maka selanjutnya peneliti akan menganalisis data sebagai tindak lanjut penelitian ini, dengan menggunakan metode kualitatif yang berlandaskan pada filsafat postpositivisme. Sesuai data yang sudah di ketahui tentang strategi rekrutmen peserta didik baru dalam masa pandemi covid-19 di SMK Darussalam Blokagung. Dalam strategi rekrutmen setiap lembaga pasti mempunyai strategi tersendiri untuk menarik minat peserta didik baru.

Strategi merupakan suatu unsur penting dalam kegiatan untuk mencapai tujuan. Khususnya dalam bidang pendidikan, strategi rekrutmen peserta didik sangat mempengaruhi keberlangsungan kegiatan belajar mengajar disekolah. Selain itu, strategi rekrutmen peserta didik baru juga dibutuhkan sebagai usaha untuk tetap mempertahankan lembaga pendidikan yaitu sekolah, tidak terkecuali bagi SMK Darussalam Blokagung.

Sebagaimana pendapat Ali Imron (2011:43) dalam bukunya "Manajemen Peserta Didik Berbasis Sekolah” ada 2 strategi dalam rekrutmen peserta didik yaitu:

\section{a. Strategi Promosi}

Strategi Rekrutmen Peserta Didik Baru Dalam Masa Pandemi Covid-19 Di SMK Darussalam Eko Budiywono, Liya Kholifatus Sholekhah 
Strategi yang digunakan oleh SMK adalah strategi promosi yang mana mereka yang mendaftar sebagai peserta didik di sekolah akan diterima semua begitu saja, mereka yang mendaftar menjadi peserta didik baru tidak ada yang ditolak.

Dalam strategi promosi kualitas sekolah akan mempengaruhi, sehingga sekolah dituntut untuk memberikan produk atau layanan pendidikan yang memiliki nilai jual tinggi, lebih lagi setiap apa yang dihasilkannya memiliki inovasi yang dapat membedakan antara sekolah tersebut dengan sekolah lainnya.

Pada tahun 2020 SMK Darussalam Blokagung mengalami penurunan jumlah peserta didik. Namun setelah dilakukan berbagai inovasi melalui strategi-strategi yang telah disusun maka pada tahun 2021 jumlah peserta didik bertambah, bahkan sampai menutup pendaftaran. Berdasarkan data yang diperoleh menunjukkan bahwa jumlah peserta didik yang mendaftar di SMK Darussalam Blokagung telah mengalami peningkatan yang cukup signifikan.

Ada beberapa upaya yang di lakukan oleh SMK Darussalam blokagung terkait dengan strategi rekrutmen yakni:

1. Sumber daya manusia

Dari segi sumber daya manusia yang dilakukan dalam rangka strategi rekrutmen peserta didik yaitu peningkatan mutu SDM, pemenuhan SDM yang dibutuhkan dan pemberdayaan SDM yang sudah ada, agar masyarakat sekitar percaya kepada sekolah ketika menyekolahkan anaknya di SMK Darussalam Blokagung karena dilihat dari segi pendidikannya yang berkualitas.

\section{Sarana prasarana}

Dari segi prasarana SMK Darussalam Blokagung terus berupaya memenuhi sarana dan prasarana penunjang pembelajaran siswa, seperti gedung sekolah, alat praktek dan sarana prasarana lainnya.

3. Membuka jurusan baru

Strategi Rekrutmen Peserta Didik Baru Dalam Masa Pandemi Covid-19 Di SMK Darussalam Eko Budiywono, Liya Kholifatus Sholekhah 
Yang dilakukan oleh SMK Darussalam Blokagung untuk strategi rekrutmen yaitu dengan menambah membuka jurusan baru yang awalnya 5 juruan kemudian membuka 1 jurusan lagi. Jurusan tersebut tentunya disesuaikan dengan potensi masyarakat dan kebutuhan dunia kerja.

4. Media

Media merupakan hal yang sangat penting dalam ajang promosi yang dilakukan untuk strategi rekrutmen. Perkembangan teknologi telah mempermudah cara promosi, salah satunya dengan munculnya berbagai media-media yang dapat mempromosikan sekolah. Di dalam sebuah lembaga pendidikan, media yang sangat diperlukan guna meningkatkan pendaftar. Melalui media yang digunakan diharapkan dapat menyampaikan serta informasi mengenai profil SMK Darussalam Blokagung sehingga di buat semenarik mungkin.

Adapun media yang digunakan di SMK Darussalam Blokagung dalam rangka strategi rekrutmen diantaranya adalah brosur, pamflet, spanduk dan semua media sosial. Sebagaimana penjelasan berikut:

a. Brosur

Brosur ini berisi mengenai informasi jurusan yang ditawarkan di SMK Darussalam Blokagung beserta failitas yang tersedia, syarat pendaftaran, alamat sekolah, dan sebagainya. Brosur mengenai profil SMK Darussalam Blokagung ini akan dibagikan ke mayarakat ketia sosialisasi kesekolah sekitar.

b. Pamflet

Pamflet ini memuat beberapa terkait SMK Darussalam Blokagung, tujuan penggunaan pamflet ini adalah untuk menarik masyarakat sehingga mereka mengetahui SMK Darussalam Blokagung.

c. Spanduk

Spanduk ini memuat tanggal pendaftaran dan hal-hal yang mengenai SMK Darussalam Blokagung untuk menarik masyarakat. Melalui spanduk orang

Strategi Rekrutmen Peserta Didik Baru Dalam Masa Pandemi Covid-19 Di SMK Darussalam Eko Budiywono, Liya Kholifatus Sholekhah 
dapat mengetahui informasi mengenai pendaftaran tersebut dibuka. Kelebihan spanduk dapat menginformasikan kepada masyarakat terutama pengguna sarana umum baik jalan, sekolah atau yang lainnya secara langsung. Namun berbagai informasi detail sekolah tidak dapat dimuatkan semua dalam spanduk, sebab spanduk hanya dapat memuat isi atau kontenkonten yang bersifat jelas padat dan menarik perhatian. Pemasangan spanduk SMK Darussalam Blokagung membuat panitia khusus dan melibatkan alumni-alumni.

d. Media sosial

SMK Darussalam Blokagung memiliki sebuah media soial yang dapat diakse seperti WA, facebook, youtube, Ig, TV dan lain-lain.

5. Kunjungan ke sekolah terdekat

Ketika menjelang penerimaan peserta didik baru (PPDB) pihak sekolah melakukan promosi ke Sekolah terdekat seperti Mts. Alamiriyah dan SMP Plus Darussalam. Kegiatan promosi tersebut melibatkan guru dan siswa untuk mengadakan presentasi seputar profil dan juga menyampaikan berbagai keunggulan SMK Darussalam Blokagung, syarat-syarat pendaftaran dan fasilitas yang disediakan bagi peserta didik yang akan bersekolah di sekolah tersebut.

SMK Darussalam Blokagung juga menghimbau kepada siswa, guru dan para alumni untuk ikut serta dalam program promosi, untuk mengenalkan sekolah kepada masyarakat sekitar untuk mendaftar di SMK Darussalam Blokagung. Itu akan menjadi elemen yang sangat besar pengaruhnya dalam strategi rekrutmen.

SMK Darussalam Blokagung juga bekerjasama dengan beberapa desa untuk menyaring anak yang kurang mampu, dan juga pesantren tujuannya juga untuk menyaring santri yang menengah kebawah untuk menawarkan beberapa beasiswa

Strategi Rekrutmen Peserta Didik Baru Dalam Masa Pandemi Covid-19 Di SMK Darussalam Eko Budiywono, Liya Kholifatus Sholekhah 
Pihak pelaksanaan yang bertanggungjawab atas pelaksanaan rekrutmen adalah WKS. Kesiswaan selaku ketua panitia PPDB, tujuannya agar lebih memundahkan dalam pelaksanaan, evaluasi nantinya dan juga memudahkan dalam pengumpulan seluruh data-data yang ada disentralkan secara global.

Proses rekrutmen peserta didik baru di SMK Darussalam Blokagung yaitu dengan pembentukan panitia, persiapan tempat dan perlengkapan, pelaksanaan PPDB, dan yang terakhir evaluasi kegiatan. Rekrutmen peserta didik yang dilakukan SMK Darussalam Blokagung sudah sangat matang yang mulai dari pembentukan panitia sampai dengan evaluasi.

Pembentukan panitia rekrutmen peserta didik baru menjelang rekrutmen peserta didik baru, juga merupakan salah satu strategi sekolah dalam memaksimalkan rekrutmen peserta didik. Dengan adanya panitia PPDB maka tugas dalam melaksanakan strategi rekrutmen mulai dari peningkatan mutu sumber daya manusia hingga kunjungan kesekolah terdekat lebih terstruktur dan terorganisir, dengan demikian panitia dapat seimbang dalam mengemban tugas pelaksanaan strategi rekrutmen PPDB.

Evaluasi dilakukan untuk menilai sejauh mana panitia PPDB dapat menjalankan tugasnya sesuai apa yang ditugaskan. Tanggungjawab panitia terhadap tugasnya masing-masing juga perlu dibuktikan dengan adanya hasil rekrutmen yang berkualitas. Keberhasilan dalam sebuah pembelajaran akan dipengaruhi oleh kualitas siswa yang dibutuhkan oleh pihak lembaga pendidikan tersebut.

b. Strategi Seleksi

Strategi seleksi yang ada di SMK Darussalam Blokagung hanya untuk pemantapan jurusan bukan untuk diterima atau tidaknya peserta didik tersebut. Pemantapan jurusan ini menggunakan tes interview pada peserta didik. Semisal TKJ tidak boleh buta warna karna akan menyulitkan siswa itu sendiri, tetapi jika siswa tersebut bersekiras untuk tetap masuk pada jurusan itu, maka akan tetap diterima.

Strategi Rekrutmen Peserta Didik Baru Dalam Masa Pandemi Covid-19 Di SMK Darussalam Eko Budiywono, Liya Kholifatus Sholekhah 
Sebagaimana Surat Edaran Nomor 4 Tahun 2020 isinya tentang Pelaksanaan Kebijakan Pendidikan Dalam Masa Darurat Penyebaran Coronavirus Disease (Covid-19). Di dalam surat edaran terebut selain menjelaskan UN dibatalkan, juga menjelaskan mengenai pelaksanaan Penerimaan Peserta Didik Baru (PPDB) 2020. Adapun PPDB 2020 dilaksanakan dengan ketentuan, salah satunya adalah dinas pendidikan dan sekolah diminta menyiapkan mekanisme PPDB yang mengikuti protokol kesehatan untuk mencegah penyebaran Covid-19. Termasuk mencegah berkumpulnya siswa dan wali secara fisik disekolah. Tidak terkecuali SMK Darussalam Blokagung juga menerapkan protokol keehatan seperti ssaat kunjungan keekolah terdekat. SMK Darussalam Blokagung menghimbau kepada seluru guru dan siswa untuk menjaga jarak dan selalu memakai masker.

Strategi yang digunakan di SMK Darussalam sudah sangat bagus, ini menunjukan adanya peningkatan jumlah peserta didik pertahunnnya. Tetapi perlu tindak lanjut untuk dimusyawarahkan kepada semua komponen sekolah untuk mengatasi hambatan-hambatan yang dihadapi dalam rekrutmen peserta didik baru, untuk lebih memberikan layanan yang terbaik terhadap konsumen agar masyarakat bisa percaya terhadap lembaga tersebut.

Dalam strategi rekrutmen peserta didik baru di SMK Darussalam blokagung terdapat faktor yang mendukung terhadap jalannya strategi rekrutmen yaitu:

1. SMK Darussalam Blokagung berada dalam naungan pondok pesantren Darussalam Blokagung

Sesuai dengan kultur SMK Darussalam Blokagung yang berada dalam naungan pondok pesantren Darussalam Blokagung, pondok pesantren yang sudah terkenal berbagai penjuru. Sehingga ini lebih memudahkan sekolah dalam menjalankan strategi rekrutmen yang dilakukannya, usia pondok pesantren yang sudah cukup lama berdiri dan 
keberadaannya yang sudah cukup diketahui oleh masyarakat, membuat pelaksanaannya lebih mudah dilaksankan. Karena SMK Darussalam Blokagung adalah salah satu lembaga yang berada di dalam pondok pesantren Darussalam Blokagung. Situasi ini ditangkap dengan baik oleh para pengelola sekolah, khususnya pada saat-saat masa rekrutmen peserta didik.

2. Semua warga sekolah ikut berpartisipasi dalam program promosi

Semua komponen sekolah seperti guru, siswa dan alumnialumni yang berpartisipasi secara aktif dalam penyelanggaraan program promosi yang dilakukan oleh sekolah. Warga sekolah adalah salah satu sasaran dalam strategi rekrutmen peserta didik baru yang bertugas sebagai garden terdepan ajang promosi, semua dihimbau untuk mempromosikan sekolahnya kepada lingkungan sekitarnya.

3. Promosi dilakukan dengan menggunakan media seperti brosur, pamflet, spanduk dan berbagai media sosial.

Faktor penghambat dalam rekrutmen peserta didik baru yaitu pertama dari segi internal yaitu letak geografis, letak geografis sekolah bisa menjadi pengaruh terhadap minat calon peserta didik baru yang akan mendaftar di SMK Darussalam Blokagung, karena letak sekolah berada dibagian paling timur pulau Jawa. Kedua dari segi eksternal yaitu orang tua wali murid banyak yang protes dalam mengenai pembayaran karna masa pandemi.

Tetapi faktor penghambat tersebut dapat diatasi oleh SMK Darussalam seperti mengenai pembayaran bisa ditanggung oleh sekolah, jadi orangtua wali bisa mencicilan dalam pembayaran.

\section{Kesimpulan}

Berdasarkan hasil penelitian yang telah dilakukan oleh peneliti, menghasilkan kesimpulan sebagai berikut:

Strategi Rekrutmen Peserta Didik Baru Dalam Masa Pandemi Covid-19 Di SMK Darussalam Eko Budiywono, Liya Kholifatus Sholekhah 
1. Strategi rekrutmen peserta didik baru dalam masa pandemi covid1-19 di SMK Darussalam Blokagung telah berjalan dengan efektif. Strategi yang gunakan strategi promosi, dimana mereka yang mendaftar menjadi peserta didik baru tidak ada yang ditolak. Ada beberapa upaya yang di lakukan oleh SMK Darussalam blokagung terkait dengan strategi rekrutmen yaitu: meningkatkan sumber daya manusia (SDM), melengkapi sarana dan prasarana, membuka jurusan baru, menggunakan media, sosialisasi kepada sekolah terdekat. Selain itu, para alumni menjadi elemen yang paling besar pengaruhnya dalam menyampaikan komunikasi ini. Strategi seleksi, yang ada disekolah hanya untuk pemantapan jurusan bukan untuk diterima atau tidaknya peserta didik tersebut.

2. Faktor pendukung dan faktor penghambat dalam strategi rekrutmen peserta didik

a. Faktor pendukung

1. Sekolah berada dibawah naungan Pondok Pesantren Darussalam Blokagung yang sudah sangat terkenal dan sudah lama berdiri.

2. Semua komponen sekolah seperti guru, siswa dan alumni-alumni yang berpartisipasi secara aktif dalam penyelanggaraan program-program yang dilakukan oleh sekolah.

3. Promosi dilakukan dengan menggunakan media seperti brosur, pamflet, spanduk dan berbagai media sosial.

b. Faktor penghambat

Segi internal yaitu letak geografis sekolah dan segi biaya. Letak geografis sekolah yang berada di bagian timur pulau Jawa, bisa menjadi pengaruh terhadap minat calon peserta didik baru yang akan mendaftar. Segi ekstenal yaitu orangtua wali murid. Orangtua murid banyak yang protes dalam mengenai pembayaran karna masa pandemi.

\section{E. Daftar Pustaka}

Efferi, Adri. (2019). Strategi Rekrutmen Peserta Didik Baru Untuk Meningkatkan 
Vol. 3, No. 1: 17-31, April 2021

ISSN: 2722-7146 (Media Online)

Keungggulan Kompetentif di MA Nahdlotul Muslimin Undaan Kadus. Jurnal:

Edukasia, penelitian pendidikan Islam IAIN Purwokerto (http://repository.iainpurwokerto.ac.id/3116/1/COVER_BAB\%20I_BAB\%20

V_DAFTAR\%20PUSTAKA.pdf, diakses 08 April 2021)

Fauzan. (2017). Strategi Rekrutmen Peserta Didik Baru di MTs Satu Atap Mubtadi'in

Purwojati dan MTs Satu Atap Biroyatul Huda Cilongko Kabupaten Banyuwas. Skripsi: Program Studi Manajemen Pendidikan Islam Pascasarjana IAIN Purwokerto (https://journal.iainkudus.ac.id/index.php/Edukasia/article/4844/pdf, diakses 08 april 2021)

Imron, Ali. (2011). Manajemen Peserta Didik Berbasis Sekolah. Jakarta: Bumi Aksara

Lestari, Endah. (2017). Sistematika Rekrutmen Peserta Didik Baru Berbasis Jaringan Sosial di SMK Ma'arif NU 2 Ajibarang Kabupaten Banyumas. Skripsi: Jurusan Manajemen Pendidikan Islam, Fakultas Tarbiyah dan Ilmu Keguruan IAIN Purwokerto

(https://ejournal.bsi.ac.id/ejurnal/index.php/infortech/article/view/9122/4551, diakses 08 April 2021)

Nur, Junaidi Joni. (2019). Strategi Kepala Seklah Dalam Rekrutmen Penerimaan Peserta Didik Baru di Sekolah Menengah Atas Negeri 5 Negeri Merangin. Skripsi: Pascasarjana, UIN Sulthan Thaha Saifuddin Jambi (https://ejournal.bsi.ac.id/ejurnal/index.php/infortech/article/view/9122/455, diakses 10 April 2021)

Azizah, Nur. (2018). Implementasi Strategi Pemasaran dalam Menarik Minat Peserta Didik di MTs Muhammadiyah Masaran Sragen Tahun Ajaran 2018/2019. Sragen:

(https://ejournal.bsi.ac.id/ejurnal/index.php, diakses 10 April 2021)

Syafiqa, Rismila. (2020). Manajemen Penerimaan Siswa Baru Berbasisi Daring di SMK Darussalam Karangpucung Cilacap. Skripsi: Jurusan Manajemen Pendidikan Islam, Fakultas Tarbiyah dan Ilmu Keguruan IAIN Purwokerto

Strategi Rekrutmen Peserta Didik Baru Dalam Masa Pandemi Covid-19 Di SMK Darussalam Eko Budiywono, Liya Kholifatus Sholekhah 
Vol. 3, No. 1: 17-31, April 2021

ISSN: 2722-7146 (Media Online)

(http://repository.iainpurwokerto.ac.id/2583/1/COVER_ABSTRAK_DAFTA R\%20ISI_BAB\%20I_BAB\%20V_\%20DAFTAR\%20PUSTAKA_LAMPIRA

N.pdf, diakses 08 April 2021)

Arikunto. Suharsimi. (2003). Manajemen Strategi. Jakarta: Reneka Cipta

Sanjaya, Wina. (2007). Strategi Pembelajaran. Jakarta: Kencana

Sugiyono. (2015). Metode Penelitian Pendidik. Bandung: Alfabeta

Subbeh, R. (2020). Pelaksana Kebijakan Pendidikan Masa Darurat Penyebaran Covid19.(https://www.jogloabang.com/pendidikan/se-4-2020-pelaksanaankebijakan-pendidikan-masa-darurat-penyebaran-covid-19 09 April 2021)

Strategi Rekrutmen Peserta Didik Baru Dalam Masa Pandemi Covid-19 Di SMK Darussalam Eko Budiywono, Liya Kholifatus Sholekhah 